\title{
The Relationship Between Abdominal Body Composition and Metabolic Syndrome After a Weight Reduction Program in Adult Men with Obesity
}

This article was published in the following Dove Press journal:

Diabetes, Metabolic Syndrome and Obesity: Targets and Therapy

\author{
Chun-Cheng Liao $\mathbb{D D}^{1,2}$ \\ Wayne Huey-Herng Sheu ${ }^{3-5}$ \\ Shih-Yi Lin ${ }^{4,6}$ \\ Wen-Jane Lee $^{7}$ \\ I-Te Lee (iD ${ }^{3,4,8,9}$ \\ 'Department of Family Medicine, \\ Taichung Armed Forces General Hospital, \\ Taichung, Taiwan; ${ }^{2}$ School of Medicine, \\ National Defense Medical Center, Taipei, \\ Taiwan; ${ }^{3}$ Division of Endocrinology and \\ Metabolism, Department of Internal \\ Medicine, Taichung Veterans General \\ Hospital, Taichung, Taiwan; ${ }^{4}$ School of \\ Medicine, National Yang-Ming University, \\ Taipei, Taiwan; ${ }^{5}$ Rong Hsing Research \\ Center for Translational Medicine, \\ College of Life Sciences, National Chung \\ Hsing University, Taichung, Taiwan; \\ ${ }^{6}$ Center for Geriatrics and Gerontology, \\ Taichung Veterans General Hospital, \\ Taichung, Taiwan; ${ }^{7}$ Department of \\ Medical Research, Taichung Veterans \\ General Hospital, Taichung, Taiwan; \\ ${ }^{8}$ School of Medicine, Chung Shan Medical \\ University, Taichung, Taiwan; ${ }^{9}$ College of \\ Science, Tunghai University, Taichung \\ City, Taiwan
}

Correspondence: I-Te Lee

Division of Endocrinology and

Metabolism, Department of Internal

Medicine, Taichung Veterans General

Hospital, 1650 Taiwan Boulevard, Sect. 4,

Taichung 40705, Taiwan

Tel +886-4-2374I 300

Fax +886-4-23593662

Email itlee@vghtc.gov.tw
Purpose: To assess the relationship between changes in abdominal adipose tissue and metabolic syndrome (MetS) in men with obesity after a weight reduction program (WRP).

Patients and Methods: Adult men with obesity and MetS were recruited for this prospective single-arm intervention study. Participants consumed an energy-restricted diet of $1200 \mathrm{kcal} /$ day and performed 50-mins aerobic exercise daily for 12 weeks. Changes in the components of MetS were recorded. Changes in subcutaneous abdominal fat area (SAFA) and intra-abdominal fat area (IAFA) at the umbilicus level were determined using magnetic resonance imaging.

Results: A total of 30 men (mean age, $42.3 \pm 10.0$ years; body mass index, $33.7 \pm 4.1 \mathrm{~kg} / \mathrm{m}^{2}$ ) were included in this study. A moderate $(8.0 \%)$ weight reduction occurred. Reversion of MetS was observed in $15(50 \%)$ participants after the WRP. There was significant reduction in SAFA (68.3 \pm 20.2 vs. $\left.51.5 \pm 18.6 \mathrm{~cm}^{2} ; P<0.001\right)$ and IAFA $\left(96.3 \pm 15.6\right.$ vs. $\left.86.0 \pm 16.5 \mathrm{~cm}^{2} ; P<0.001\right)$; the magnitude of reduction was greater for SAFA than for IAFA $\left(-16.8 \pm 7.7 \mathrm{vs} .-10.3 \pm 8.3 \mathrm{~cm}^{2}\right.$; $P<0.001)$. Multivariate logistic regression analysis showed a reduction in IAFA to be an independent factor to decrease the risk of persistent MetS after WRP by adjustment for age, baseline IAFA, and change in SAFA (odds ratio $=0.25,95 \%$ confidence interval: $0.07-0.95$, $P=0.041)$. Reduction in SAFA was not significantly associated with the reversion of MetS $(P=0.411)$.

Conclusion: Reduction in IAFA via a 12-week WRP may help reverse MetS in men with obesity and MetS.

Keywords: body mass index, intra-abdominal fat, magnetic resonance imaging, metabolic syndrome, subcutaneous abdominal fat, visceral fat

\section{Introduction}

Obesity, characterized by an excessive proportion of body fat, is associated with chronic complications, including cardiovascular disease, type 2 diabetes mellitus, and cancer. ${ }^{1}$ Obesity has become a growing health problem worldwide. ${ }^{2-4}$ Data from the Nutrition and Health Survey in Taiwan showed that the prevalence of obesity, defined by body mass index $(\mathrm{BMI}) \geq 27 \mathrm{~kg} / \mathrm{m}^{2}$, was approximately $22.1 \%$ between 2013 and $2014 .^{5}$

Abdominal obesity, characterized by increased waist circumference, is a relevant health issue. ${ }^{6-8}$ Generally, abdominal fat can be divided into subcutaneous and intraabdominal fat. ${ }^{9}$ Although intra-abdominal fat, both visceral and retroperitoneal fat, 
represents approximately $15 \%$ of the total body fat, it is closely associated with cardiovascular disease and mortality. ${ }^{10}$ Previous studies have indicated that intra-abdominal adipose tissue, but not subcutaneous abdominal one, is associated with insulin resistance and cardiovascular risks. ${ }^{6}$

Metabolic syndrome (MetS) comprises a cluster of abnormal components based on physiological, clinical, and metabolic factors that directly increase the risk of type 2 diabetes mellitus and cardiovascular morbidity and mortality. ${ }^{11-13}$ Abdominal obesity, one of the MetS components, should be considered a critical mechanism linking MetS and cardiovascular disease. ${ }^{14}$ Intraabdominal fat has been reported as a long-term predictor of insulin resistance in a longitudinal observation. ${ }^{15}$

Physical activity along with restriction of energy intake is an effective first-line strategy to manage obesity. ${ }^{16}$ Weight reduction has been reported to improve cardiovascular risks in subjects with obesity after such a short-term intervention. $^{17-19}$ A greater loss of subcutaneous fat than of visceral fat was observed in the whole body as well as abdominal area among the majority of weight reduction programs (WRP). ${ }^{20}$ However, it is reported that visceral fat was a better predictor of insulin resistance, MetS, and mortality. ${ }^{21,22}$ We hypothesized that a reduction in visceral fat would have a stronger contribution to the improvement of MetS than a reduction in subcutaneous fat. Therefore, we assessed intra-abdominal fat area (IAFA) and subcutaneous abdominal fat area (SAFA) before and after WRP in men with obesity and MetS.

\section{Materials and Methods}

\section{Participants}

This prospective, single-arm interventional study was conducted at Taichung Veterans General Hospital in Taiwan. The inclusion criteria were (1) adult men, (2) age between 20 and 75 years, (3) MetS, and (4) BMI $\geq 27 \mathrm{~kg} / \mathrm{m}^{2}$, the cutoff for defining obesity in Taiwan. ${ }^{23}$ The exclusion criteria were (1) current use of antidiabetic medications, medications for psychological disorders, and medications affecting body weight, such as systemic steroids; (2) changes in antihypertensive, lipid-lowering, or antiplatelet drugs within the past month; (3) endocrine diseases, such as thyroid or adrenal disorders; (4) acute or chronic kidney diseases with serum creatinine levels $>200 \mu \mathrm{mol} / \mathrm{L}$; (5) severe systemic diseases, such as malignant or immune disorders; and (6) addiction to alcohol or drugs.

\section{Weight Reduction Program}

Participants enrolled in this study were required to decrease body weight via a 12-week program of intake restriction and exercise promotion. They were instructed by a dietitian to maintain a $1200 \mathrm{kcal} /$ day diet, divided into $300 \mathrm{kcal}$ at breakfast, $400 \mathrm{kcal}$ at lunch, and $500 \mathrm{kcal}$ at dinner. Participants were encouraged to undertake aerobic exercise for 50 mins daily. During the WRP, all subjects attended eight classes for the purpose of lifestyle training. The first three classes were held every week, and the others were held every 2 weeks. Each class included: anthropometric assessments by a study nurse; diet diaries reviewed by a registered dietitian; exercise target setting by a trained instructor; and group discussion among the participants, the dietitian, the cardiologist, and the endocrinologist. Following the class, subjects were required to attend a 50-min practice session for moderate-intensity aerobic exercise, which was provided by trained instructors in the presence of doctors.

A $10 \%$ reduction in basal body weight was suggested, ${ }^{24,25}$ and no medication changes were allowed during the study. The study was approved by the Institutional Review Board of Taichung Veterans General Hospital, and written informed consent was obtained by all participants. This study was conducted in accordance with the Declaration of Helsinki.

\section{Measurements}

Anthropometric parameters, blood pressure, fasting glucose, insulin, lipid profiles, abdominal fat content, and number of MetS components at baseline and at the end of the 12-week WRP were assessed. Height was measured (Pharmacia Taiwan Inc., Taipei, Taiwan) after participants had removed their shoes, and body weight (DETECTO, Cardinal Scale Manufacturing Co., Webb City, MO, USA) after they had taken off all heavy clothing. BMI was calculated as weight $(\mathrm{kg})$ divided by height $\left(\mathrm{m}^{2}\right)$. Waist circumference was measured midway between the lowest rib and iliac crest using a measuring tape (kp-1508, King Life, Taipei, Taiwan). Blood pressure was recorded in the sitting position using the DINAMAP ${ }^{\mathrm{TM}}$ Vital Signs Monitor (Model $1846 \mathrm{SX} / \mathrm{P}$ ) after participants had rested for $10 \mathrm{mins}$; three readings were taken at intervals of $1 \mathrm{~min}$ and the average of the second and the third readings was registered. Blood samples were collected after an overnight fast. Fasting glucose and lipid levels were measured using commercial kits (Beckman Coulter, Fullerton, 
CA, USA). Insulin was measured using commercial kits (Roche Diagnostics GmbH, Mannheim, Germany). The homeostasis model assessment of insulin resistance (HOMA-IR) index was calculated as fasting insulin (mg/ $\mathrm{dL}) \times$ fasting glucose $(\mathrm{mmol} / \mathrm{L}) / 405{ }^{26}$ Adipose tissue depots were measured using magnetic resonance imaging (MRI) (Siemens Medical Systems, Iselin, NJ, USA), and dedicated software (Leonardo, Siemens Healthcare, Germany) was used to determine the IAFA and SAFA at the level of the umbilicus. ${ }^{27}$ The IAFA/SAFA ratio (ISR) was calculated. We used the harmonized definition of MetS. ${ }^{28}$ The criteria of abnormal components are as follows: (1) waist circumference $\geq 90 \mathrm{~cm}$, (2) fasting glucose $\geq 100 \mathrm{mg} / \mathrm{dL}$, (3) blood pressure $\geq 130 / 85 \mathrm{mmHg}$, (4) triglycerides $\geq 150 \mathrm{mg} / \mathrm{dL}$, and (5) high-density lipoprotein (HDL) cholesterol $<40 \mathrm{mg} / \mathrm{dL}$. The number of MetS components was calculated as the sum of all abnormal components, and the definition of MetS was the number of MetS components $\geq 3$ in each individual.

\section{Statistical Analysis}

Continuous variables were summarized as mean \pm standard deviation and categorical variables as frequency and percentage. The normality of distribution of data was examined using the Kolmogorov-Smirnov test. The changes in parameters between baseline and the end of the WRP were examined using the Wilcoxon signed-rank test for continuous variables or the McNemar's test for categorical variables. The correlation was assessed using the Spearman correlation coefficient. Multivariate logistic analysis was used to identify the independent predictors for the reversion of MetS after the WRP. Two-sided $P<0.05$ was taken to indicate statistical significance. SPSS 22.0 (IBM, Armonk, NY, USA) was used for statistical analysis.

\section{Results}

Out of the 40 candidates initially identified, six were excluded according to the criteria; another four dropped out of the study. Thus, a total of 30 participants completed the WRP and MRI assessments. The mean age was $42.3 \pm$ 10.0 years, and an $8.0 \%$ weight reduction (from $98.3 \pm$ $13.4 \mathrm{~kg}$ to $90.4 \pm 14.2 \mathrm{~kg}, P<0.001)$ was observed after the WRP. Table 1 shows the characteristics of the participants before and after the WRP. BMI and waist circumference were significantly decreased after the WRP $(33.7 \pm 4.1$ vs. $31.0 \pm 4.4 \mathrm{~kg} / \mathrm{m}^{2}, P<0.001 ; 109.7 \pm 9.6$ vs. $101.6 \pm$ $10.8 \mathrm{~cm}, P<0.001$; respectively). Systolic and diastolic blood pressures were significantly decreased after the WRP
Table I Characteristics of All Participants Before and After the Weight Reduction Program

\begin{tabular}{|c|c|c|c|}
\hline & \multicolumn{2}{|c|}{$\begin{array}{l}\text { Weight Reduction } \\
\text { Program }\end{array}$} & \multirow[t]{2}{*}{$P$} \\
\hline & $\begin{array}{l}\text { Before } \\
(n=30)\end{array}$ & $\begin{array}{l}\text { After } \\
(n=30)\end{array}$ & \\
\hline Age (years) & $42.3 \pm 10.0$ & & \\
\hline BMI $\left(\mathrm{kg} / \mathrm{m}^{2}\right)$ & $33.7 \pm 4.1$ & $31.0 \pm 4.4$ & $<0.001$ \\
\hline Body weight (kg) & $98.3 \pm 13.4$ & $90.4 \pm 14.2$ & $<0.001$ \\
\hline Waist circumference $(\mathrm{cm})$ & $109.7 \pm 9.6$ & $101.6 \pm 10.8$ & $<0.001$ \\
\hline Systolic BP (mmHg) & $136.5 \pm 17.1$ & $121.5 \pm 17.9$ & 0.001 \\
\hline Diastolic BP (mmHg) & $82.7 \pm 11.1$ & $73.8 \pm 12.7$ & $<0.001$ \\
\hline Fasting glucose (mg/dL) & $102.5 \pm 15.7$ & $96.9 \pm 9.7$ & 0.008 \\
\hline HDL cholesterol (mg/dL) & $38.3 \pm 7.0$ & $41.9 \pm 10.4$ & 0.023 \\
\hline Triglycerides (mg/dL) & $316.4 \pm 485.2$ & $201.9 \pm 279.3$ & 0.008 \\
\hline HOMA-IR & $5.0 \pm 3.2$ & $3.1 \pm 1.5$ & $<0.001$ \\
\hline Number of MetS components & $3.8 \pm 0.8$ & $2.5 \pm 1.5$ & $<0.001$ \\
\hline IAFA $\left(\mathrm{cm}^{2}\right)$ & $96.3 \pm 15.6$ & $86.0 \pm 16.5$ & $<0.001$ \\
\hline SAFA $\left(\mathrm{cm}^{2}\right)$ & $68.3 \pm 20.2$ & $51.5 \pm 18.6$ & $<0.001$ \\
\hline ISR & $1.5 \pm 0.4$ & $1.8 \pm 06$ & $<0.001$ \\
\hline
\end{tabular}

Abbreviations: $\mathrm{BMI}$, body mass index; BP, blood pressure; HDL, high-density lipoprotein; HOMA-IR, homeostatic model assessment of insulin resistance; IAFA, intra-abdominal fat area; ISR, intra-abdominal fat area/subcutaneous abdominal fat area ratio; MetS, metabolic syndrome; SAFA, subcutaneous abdominal fat area.

$(136.5 \pm 17.1$ vs. $121.5 \pm 17.9 \mathrm{mmHg}, P=0.001 ; 82.7 \pm$ 11.1 vs. $73.8 \pm 12.7 \mathrm{mmHg}, P<0.001$; respectively). Plasma glucose was significantly decreased $(102.5 \pm 15.7$ vs. $96.9 \pm 9.7 \mathrm{mg} / \mathrm{dL}, P=0.008)$. Fasting triglycerides and HDL cholesterol were significantly improved after the WRP $(316.4 \pm 485.2$ vs. $201.9 \pm 279.3 \mathrm{mg} / \mathrm{dL}, P=0.008$; $38.3 \pm 7.0$ vs. $41.9 \pm 10.4 \mathrm{mg} / \mathrm{dL}, P=0.023$; respectively). The IAFA and SAFA were significantly decreased after the WRP $\left(96.3 \pm 15.6\right.$ vs. $86.0 \pm 16.5 \mathrm{~cm}^{2}, P<0.001 ; 68.3 \pm$ 20.2 vs. $\left.51.5 \pm 18.6 \mathrm{~cm}^{2}, P<0.001\right)$ respectively. There was a greater reduction in SAFA than in IAFA $(-16.8 \pm 7.7 \mathrm{vs.}$ $\left.-10.3 \pm 8.3 \mathrm{~cm}^{2}, P<0.001\right)$

At the end of the 12-week WRP, 15 (50\%) participants had reversion of MetS and the other 15 (50\%) participants had persistent MetS ( $P<0.001$ based on McNemar's test). The mean number of MetS components was significantly decreased in participants with reversion of MetS after the WRP $(3.5 \pm 0.7$ vs. $1.3 \pm 0.8, P<0.001)$ but not in those with persistent MetS $(4.0 \pm 0.8$ vs. $3.7 \pm 0.9, P=0.262$; Table 2). BMI, IAFA, and SAFA were significantly decreased, and ISR was significantly increased in both groups. The reduction in IAFA was significantly greater in participants with the reversion of MetS than that in participants with persistent MetS $(-14.2 \pm 7.9$ vs. $-5.9 \pm$ $\left.6.3 \mathrm{~cm}^{2}, P=0.008\right)$, but the reduction in SAFA was 
Table 2 Comparison of Participants with Persistent MetS and Participants with Reversion of MetS After the Weight Reduction Program (WRP)

\begin{tabular}{|c|c|c|c|c|c|}
\hline & $\begin{array}{l}\text { Persistent MetS After } \\
\text { WRP }(n=15)\end{array}$ & $P *$ & $\begin{array}{l}\text { Reversion of MetS After } \\
\text { WRP }(n=15)\end{array}$ & $P^{*}$ & $P^{\#}$ \\
\hline Age (years) & $45.2 \pm 10.6$ & & $41.5 \pm 9.2$ & & 0.312 \\
\hline \multicolumn{6}{|l|}{ BMI $\left(\mathrm{kg} / \mathrm{m}^{2}\right)$} \\
\hline Baseline & $32.5 \pm 3.2$ & & $33.9 \pm 4.6$ & & 0.358 \\
\hline Change & $-2.2 \pm 1.3$ & $<0.001$ & $-3.4 \pm 1.5$ & $<0.001$ & 0.031 \\
\hline \multicolumn{6}{|l|}{ Waist circumference $(\mathrm{cm})$} \\
\hline Baseline & $108.9 \pm 7.6$ & & $108.1 \pm 10.3$ & & 0.817 \\
\hline Change & $-8.6 \pm 5.3$ & $<0.001$ & $-9.3 \pm 6.3$ & $<0.001$ & 0.747 \\
\hline \multicolumn{6}{|l|}{ Systolic BP (mmHg) } \\
\hline Baseline & $137.1 \pm 16.5$ & & $135.8 \pm 18.2$ & & 0.835 \\
\hline Change & $-8.2 \pm|7|$. & 0.085 & $-21.8 \pm 23.2$ & 0.003 & 0.079 \\
\hline \multicolumn{6}{|l|}{ Diastolic BP (mmHg) } \\
\hline Baseline & $86.1 \pm 10.7$ & & $79.3 \pm 10.7$ & & 0.091 \\
\hline Change & $-7.7 \pm 9.9$ & 0.010 & $-10.1 \pm 9.8$ & 0.001 & 0.510 \\
\hline \multicolumn{6}{|l|}{ Fasting glucose (mg/dL) } \\
\hline Baseline & $106.3 \pm 19.7$ & & $98.7 \pm 9.7$ & & 0.190 \\
\hline Change & $-6.0 \pm 11.8$ & 0.070 & $-5.1 \pm 9.8$ & 0.061 & 0.829 \\
\hline \multicolumn{6}{|l|}{ HDL cholesterol (mg/dL) } \\
\hline Baseline & $37.3 \pm 5.5$ & & $39.3 \pm 8.3$ & & 0.428 \\
\hline Change & $-2.2 \pm 4.9$ & 0.105 & $9.3 \pm 6.5$ & $<0.001$ & $<0.001$ \\
\hline \multicolumn{6}{|l|}{ Triglycerides (mg/dL) } \\
\hline Baseline & $438.7 \pm 671.3$ & & $194.2 \pm 70.8$ & & 0.172 \\
\hline Change & $-|4| .| \pm 307|$. & 0.097 & $-87.9 \pm 75.2$ & $<0.001$ & 0.520 \\
\hline \multicolumn{6}{|l|}{ HOMA-IR } \\
\hline Baseline & $5.2 \pm 2.2$ & & $4.9 \pm 4.0$ & & 0.800 \\
\hline Change & $-1.8 \pm 3.4$ & 0.001 & $-1.9 \pm 1.7$ & 0.051 & 0.952 \\
\hline \multicolumn{6}{|l|}{ IAFA $\left(\mathrm{cm}^{2}\right)$} \\
\hline Baseline & $91.4 \pm 10.4$ & & $100.6 \pm 18.3$ & & 0.426 \\
\hline Change & $-5.9 \pm 6.3$ & 0.008 & $-14.2 \pm 7.9$ & $<0.001$ & 0.008 \\
\hline \multicolumn{6}{|l|}{ SAFA $\left(\mathrm{cm}^{2}\right)$} \\
\hline Baseline & $68.2 \pm 19.9$ & & $68.5 \pm 21.2$ & & 0.737 \\
\hline Change & $-14.3 \pm 6.3$ & $<0.001$ & $-19.0 \pm 8.4$ & $<0.001$ & 0.117 \\
\hline \multicolumn{6}{|l|}{ ISR } \\
\hline Baseline & $1.6 \pm 0.5$ & & $1.5 \pm 0.4$ & & 0.894 \\
\hline Change & $0.3 \pm 02$ & $<0.001$ & $0.4 \pm 0.4$ & 0.008 & 0.521 \\
\hline \multicolumn{6}{|l|}{ Number of MetS components } \\
\hline Baseline & $4.0 \pm 0.8$ & & $3.5 \pm 0.7$ & & 0.120 \\
\hline Change & $-0.3 \pm 0.9$ & 0.262 & $-2.3 \pm 1.1$ & $<0.001$ & $<0.001$ \\
\hline
\end{tabular}

Notes: *P: significance of intra-group change before and after WRP. ${ }^{*} P$ : significance of difference between the two groups.

Abbreviations: BMI, body mass index; BP, blood pressure; HDL, high-density lipoprotein; HOMA-IR, homeostasis model assessment of insulin resistance; IAFA, intraabdominal fat area; ISR, intra-abdominal fat area/subcutaneous abdominal fat area ratio; MetS, metabolic syndrome; SAFA, subcutaneous abdominal fat area; WRP, weight reduction program. 
comparable between the groups $(-19.0 \pm 8.4$ vs. $-14.3 \pm$ $\left.6.3 \mathrm{~cm}^{2}, P=0.117\right)$. Among the MetS components, only the change in HDL cholesterol was significantly different between these two groups $(9.3 \pm 6.5 \mathrm{mg} / \mathrm{dL}$ in participants with MetS reversion vs. $-2.2 \pm 4.9 \mathrm{mg} / \mathrm{dL}$ in participants with persistent MetS, $P<0.001)$. A significantly inverse correlation was observed between changes in IAFA and HDL cholesterol (Spearman's correlation coefficient = $-0.527, P=0.006$; Table 3). Target weight reduction ( $>10 \%$ of baseline body weight) was achieved by only 9 $(30 \%)$ of 30 participants. MetS reversion occurred in 2 of 9 participants who achieved target weight reduction and 13 of 21 participants who did not achieve target weight reduction $(P>0.05)$.

Multivariate logistic regression analysis estimated the association of multiple variables with persistent MetS after the WRP (Table 4). A reduction in IAFA was a significant factor to decrease the risk of persistent MetS after the WRP based on adjustments for age, SAFA change, and baseline IAFA (odds ratio $=0.25,95 \%$ confidence interval: $0.07-0.95, P=0.041)$. However, change in SAFA was not significantly associated with reversion to an absence of MetS in this logistic regression model $(P=0.411)$.

\section{Discussion}

The major finding was that IAFA reduction, but not SAFA reduction, was significantly associated with MetS reversion after the WRP. A previous cross-sectional study reported that visceral fat, but not subcutaneous fat, was associated with MetS. ${ }^{6}$ In a longitudinal study with 10year follow-up, Tong et $\mathrm{al}^{29}$ reported that baseline IAFA was predictive of the development of MetS in a 10-year observation. However, our strength in the present study is to demonstrate an independent association between IAFA reduction and MetS reversion via a WRP intervention in men with obesity and MetS. In the Multi-Ethnic Study of Atherosclerosis (MESA) study, Shah et al ${ }^{30}$ also demonstrated that an increase in visceral fat, but not subcutaneous fat, was associated with a development of MetS in subjects without MetS at baseline. Park and Lee ${ }^{31}$ demonstrated that reduction in visceral fat was significantly correlated with the reduction of fasting blood glucose and triglyceride levels after WRP. These reports are in line with our findings indicating that the change in IAFA, instead of SAFA, was an important mechanism involved in MetS, even in the development of MetS during observation and the resolution of MetS in the WRP intervention.

Table 3 Correlation Between Changes in Body Fat and Changes in BMI, HOMA-IR and Components of Metabolic Syndrome

\begin{tabular}{|l|l|l|l|l|l|l|}
\hline & IAFA & $\boldsymbol{P}$ & SAFA & $\boldsymbol{P}$ & ISR \\
\hline BMI & 0.577 & 0.002 & 0.705 & $<0.001$ & -0.263 & 0.194 \\
HOMA-IR & -0.071 & 0.729 & 0.158 & 0.442 & -0.226 & 0.267 \\
Waist circumference & 0.124 & 0.545 & 0.338 & 0.091 & -0.454 & 0.020 \\
Systolic BP & 0.150 & 0.466 & 0.426 & 0.030 & -0.114 & 0.578 \\
Diastolic BP & -0.128 & 0.533 & 0.375 & 0.059 & 0.003 & 0.987 \\
Fasting glucose & 0.011 & 0.957 & -0.123 & 0.549 & -0.106 & 0.606 \\
HDL cholesterol & -0.527 & 0.006 & -0.156 & 0.446 & -0.238 & 0.242 \\
Triglycerides & $0.48 I$ & 0.013 & 0.195 & $0.34 \mathrm{O}$ & -0.079 \\
\hline
\end{tabular}

Abbreviations: BMI, body mass index; BP, blood pressure; HDL, high-density lipoprotein; HOMA-IR, homeostasis model assessment of insulin resistance; IAFA, intraabdominal fat area; ISR, intra-abdominal fat area/subcutaneous abdominal fat area ratio; SAFA, subcutaneous abdominal fat area.

Table 4 Logistic Regression Analysis for the Effects of Associated Variables to Persistent Metabolic Syndrome After Weight Reduction Program

\begin{tabular}{|c|c|c|c|c|}
\hline & \multicolumn{2}{|l|}{ Model I } & \multicolumn{2}{|l|}{ Model 2} \\
\hline & Odds Ratio $(95 \% \mathrm{CI})$ & $P$ & Odds Ratio (95\% Cl) & $P$ \\
\hline Age & $1.02(0.94-1.12)$ & 0.606 & $1.04(0.94-1.15)$ & 0.445 \\
\hline IAFA reduction & $0.28(0.09-0.89)$ & 0.031 & $0.25(0.07-0.95)$ & 0.041 \\
\hline SAFA reduction & $0.57(0.17-1.93)$ & 0.365 & $0.61(0.19-1.97)$ & $0.41 I$ \\
\hline Baseline IAFA & & & $0.41(0.12-1.39)$ & 0.152 \\
\hline
\end{tabular}

Notes: All dependent variables were standardized after dividing by standard deviation. Model I: Multivariate logistic regression analysis including age, IAFA reduction and SAFA reduction; Model 2: Multivariate logistic regression analysis including age, IAFA reduction, SAFA reduction, and baseline IAFA.

Abbreviations: IAFA, intra-abdominal fat area; $\mathrm{Cl}$, confidence interval; SAFA, subcutaneous abdominal fat area. 
In the present study, the 12-week WPR produced a significant decrease in BMI and waist circumference. However, the target of $10 \%$ bodyweight reduction was not directly associated with the reversion of MetS. We found a greater reduction in SAFA than in IAFA in these participants with MetS. Consistent with our findings, a greater reduction in subcutaneous fat than in visceral fat was observed after lifestyle modification, weight-losspromoting drugs, and bariatric surgery in a previous metaanalysis report. ${ }^{20}$ However, it is well recognized that the accumulation of visceral fat has a stronger association with cardiovascular risks than subcutaneous fat. ${ }^{32,33}$ High expression of interleukin- 6 and monocyte chemoattractant protein has been reported in visceral adipose tissue. ${ }^{34-36}$ Visceral fat situated close to the liver may deliver inflammatory factors to the liver through the portal vein and induce hepatic steatosis and dyslipidemia. ${ }^{37,38}$ Pontiroli et $\mathrm{al}^{39}$ reported that reduction in visceral fat is more critical in cardiovascular prevention than that in subcutaneous fat after a bariatric restrictive surgery in patients with morbid obesity.

Weight reduction might lead to an improvement in inflammation and insulin resistance. ${ }^{40}$ Chae et $\mathrm{al}^{41}$ reported that inflammatory cytokines and oxidative stress attenuated after a 3-year program of calorie restriction. It has been proven that a weight reduction can reduce the incidence of type 2 diabetes in the Diabetes Prevention Program, ${ }^{42}$ and that the change in MetS severity was a good predictor of type 2 diabetes and cardiovascular disease during the long-term follow-up. ${ }^{43}$ In the present study, a significant reduction in insulin resistance and fasting plasma glucose level was observed after the WRP. The reduction in fasting glucose HOMA-IR was similar in participants with and without reversion of MetS. Visceral fat is known to be closely associated with insulin resistance, but recent reports suggest that subcutaneous fat may be also associated with insulin resistance in men. Our data suggest a general reduction in insulin resistance in all participants, but the reduction in HOMA-IR did not reach the statistical significance in a subgroup of participants with the reversion of MetS due to a wide variation in baseline HOMA-IR. ${ }^{44}$

Weight reduction results in decreased catabolism and decreased secretion of HDL apolipoproteins. ${ }^{45,46}$ Therefore, improvement in the circulating level of HDL cholesterol is not as good as the improvement in other MetS components. ${ }^{47}$ Interestingly, in the present study, reduction in IAFA was significantly correlated with an increase in HDL cholesterol, and associated with a reversion of MetS via the improvement of the component of HDL cholesterol.

We recognize several limitations in the present study. First, because there were differences between the sexes in body fat distribution and the cutoff criteria for waist circumference and HDL cholesterol in MetS, we enrolled only male participants; our results may therefore not be applicable to women. Second, the sample size was relatively small, and we could not compare the effects of WRP on MetS in different age-group strata. Although MetS prevalence is correlated with age, the association between MetS and cardiovascular risk is noted across age strata. ${ }^{48,49}$ In the present study, the effect of IAFA reduction on MetS reversion was independent of age. Third, in order to keep all subjects in a similar lifestyle, we did not design a conventional treatment as controls, and we performed a fixed program regardless of participants' baseline conditions. Fourth, we only assessed MetS before and after the WRP but did not assess long-term outcomes.

\section{Conclusion}

Reduction in IAFA was an independent factor for improved MetS after a 12-week WRP in men with obesity and MetS at baseline. The magnitude of the IAFA reduction was less than that of SAFA, but the IAFA reduction contributed a significant effect on MetS reversion compared with SAFA. Further large-scale studies are warranted to investigate the long-term benefits of intra-abdominal fat reduction.

\section{Abbreviations}

BMI, body mass index; HDL, high-density lipoprotein; HOMA-IR, homeostasis model assessment of insulin resistance; IAFA, intra-abdominal fat area; ISR, intraabdominal fat area/subcutaneous abdominal fat area ratio; MESA, multi-ethnic study of atherosclerosis; MetS, metabolic syndrome; MRI, magnetic resonance imaging; SAFA, subcutaneous abdominal fat area; WRP, weight reduction program.

\section{Ethics Approval and Informed Consent}

The study was approved by the Institutional Review Board of Taichung Veterans General Hospital, and written informed consent was obtained by all participants before the study procedures were performed. 


\section{Author Contributions}

All authors made substantial contributions to conception and design, acquisition of data, or analysis and interpretation of data; took part in drafting the article or revising it critically for important intellectual content; gave final approval of the version to be published; and agree to be accountable for all aspects of the work.

\section{Funding}

The work was supported by grants from Taichung Veterans General Hospital (TCVGH-983502A and TCVGH1083504C).

\section{Disclosure}

The authors declared no conflicts of interest in this work.

\section{References}

1. Haslam DW, James WP. Obesity. Lancet. 2005;366 (9492):1197-1209. doi:10.1016/S0140-6736(05)67483-1

2. Ng M, Fleming T, Robinson M, et al. Global, regional, and national prevalence of overweight and obesity in children and adults during 1980-2013: a systematic analysis for the Global Burden of Disease Study 2013. Lancet. 2014;384(9945):766-781. doi:10.1016/S01406736(14)60460-8

3. Seidell JC, Halberstadt J. The global burden of obesity and the challenges of prevention. Ann Nutr Metab. 2015;66(Suppl 2):7-12. doi:10.1159/000375143

4. Hwang LC, Bai CH, Chen CJ. Prevalence of obesity and metabolic syndrome in Taiwan. J Formos Med Assoc. 2006;105(8):626-635. doi:10.1016/S0929-6646(09)60161-3

5. Chang HC, Yang HC, Chang HY, et al. Morbid obesity in Taiwan: prevalence, trends, associated social demographics, and lifestyle factors. PLoS One. 2017;12(2):e0169577. doi:10.1371/journal. pone. 0169577

6. Sandeep S, Gokulakrishnan K, Velmurugan K, Deepa M, Mohan V. Visceral \& subcutaneous abdominal fat in relation to insulin resistance \& metabolic syndrome in non-diabetic south Indians. Indian $J$ Med Res. 2010;131:629-635.

7. Han TS, van Leer EM, Seidell JC, Lean ME. Waist circumference action levels in the identification of cardiovascular risk factors: prevalence study in a random sample. $B M J$. 1995;311(7017):1401-1405. doi:10.1136/bmj.311.7017.1401

8. Després JP. From syndrome $\mathrm{X}$ to cardiometabolic risk: clinical and public health implications. Proc Nutr Soc. 2019;1-7. doi:10.1017/ S0029665119001010

9. Fox CS, Massaro JM, Hoffmann U, et al. Abdominal visceral and subcutaneous adipose tissue compartments: association with metabolic risk factors in the Framingham Heart Study. Circulation. 2007;116(1):39-48. doi:10.1161/CIRCULATIONAHA.106.675355

10. Klein S, Allison DB, Heymsfield SB, et al. Waist circumference and cardiometabolic risk: a consensus statement from Shaping America's Health: association for weight management and obesity prevention; NAASO, the obesity society; the American Society for Nutrition; and the American Diabetes Association. Obesity (Silver Spring). 2007;15 (5):1061-1067. doi:10.1038/oby.2007.632

11. Lakka HM, Laaksonen DE, Lakka TA, et al. The metabolic syndrome and total and cardiovascular disease mortality in middle-aged men JAMA. 2002;288(21):2709-2716. doi:10.1001/jama.288.21.2709
12. Isomaa $\mathrm{B}$, Almgren $\mathrm{P}$, Tuomi $\mathrm{T}$, et al. Cardiovascular morbidity and mortality associated with the metabolic syndrome. Diabetes Care. 2001;24(4):683-689. doi:10.2337/diacare.24.4.683

13. Kaur J. A comprehensive review on metabolic syndrome. Cardiol Res Pract. 2014;2014:943162. doi:10.1155/2014/943162

14. Kramer CK, Zinman B, Retnakaran R. Are metabolically healthy overweight and obesity benign conditions?: A systematic review and meta-analysis. Ann Intern Med. 2013;159(11):758-769. doi:10.7326/0003-4819-159-11-201312030-00008

15. Hayashi T, Boyko EJ, McNeely MJ, Leonetti DL, Kahn SE, Fujimoto WY. Visceral adiposity, not abdominal subcutaneous fat area, is associated with an increase in future insulin resistance in Japanese Americans. Diabetes. 2008;57(5):1269-1275. doi:10.2337/ $\mathrm{db} 07-1378$

16. Cereda E, Malavazos AE, Caccialanza R, Rondanelli M, Fatati G, Barichella M. Weight cycling is associated with body weight excess and abdominal fat accumulation: a cross-sectional study. Clin Nutr. 2011;30(6):718-723. doi:10.1016/j.clnu.2011.06.009

17. Seligman BG, Polanczyk CA, Santos AS, et al. Intensive practical lifestyle intervention improves endothelial function in metabolic syndrome independent of weight loss: a randomized controlled trial. Metabolism. 2011;60(12):1736-1740. doi:10.1016/j.metabol.2011.05. 006

18. Malakou E, Linardakis M, Armstrong MEG, et al. The combined effect of promoting the mediterranean diet and physical activity on metabolic risk factors in adults: a systematic review and meta-analysis of randomised controlled trials. Nutrients. 2018;10 (11):E1577. doi:10.3390/nu10111577

19. Dvorakova-Lorenzova A, Suchanek P, Havel PJ, et al. The decrease in C-reactive protein concentration after diet and physical activity induced weight reduction is associated with changes in plasma lipids, but not interleukin-6 or adiponectin. Metabolism. 2006;55 (3):359-365. doi:10.1016/j.metabol.2005.09.010

20. Merlotti C, Ceriani V, Morabito A, Pontiroli AE. Subcutaneous fat loss is greater than visceral fat loss with diet and exercise, weight-loss promoting drugs and bariatric surgery: a critical review and meta-analysis. Int $J$ Obes (Lond). 2017;41(5):672-682. doi:10.1038/ijo.2017.31

21. Hiuge-Shimizu A, Kishida K, Funahashi T, et al. Absolute value of visceral fat area measured on computed tomography scans and obesity-related cardiovascular risk factors in large-scale Japanese general population (the VACATION-J study). Ann Med. 2012;44 (1):82-92. doi:10.3109/07853890.2010.526138

22. Kuk JL, Katzmarzyk PT, Nichaman MZ, Church TS, Blair SN, Ross R. Visceral fat is an independent predictor of all-cause mortality in men. Obesity (Silver Spring). 2006;14(2):336-341. doi:10.1038/oby.2006.43

23. Pan WH, Flegal KM, Chang HY, Yeh WT, Yeh CJ, Lee WC. Body mass index and obesity-related metabolic disorders in Taiwanese and US whites and blacks: implications for definitions of overweight and obesity for Asians. Am J Clin Nutr. 2004;79(1):31-39. doi:10.1093/ ajen/79.1.31

24. Jung RT. Obesity as a disease. Br Med Bull. 1997;53(2):307-321. doi:10.1093/oxfordjournals.bmb.a011615

25. Wadden TA, Anderson DA, Foster GD. Two-year changes in lipids and lipoproteins associated with the maintenance of a $5 \%$ to $10 \%$ reduction in initial weight: some findings and some questions. Obes Res. 1999;7(2):170-178. doi:10.1002/j.1550-8528.1999.tb00699.x

26. Matthews DR, Hosker JP, Rudenski AS, Naylor BA, Treacher DF, Turner RC. Homeostasis model assessment: insulin resistance and beta-cell function from fasting plasma glucose and insulin concentrations in man. Diabetologia. 1985;28(7):412-419. doi:10.1007/ BF00280883

27. Lee IT, Lee WJ, Tsai IC, et al. Brain-derived neurotrophic factor not associated with metabolic syndrome but inversely correlated with vascular cell adhesion molecule-1 in men without diabetes. Clin Chim Acta. 2012;413(9-10):944-948. doi:10.1016/j.cca.2012.02.013 
28. Alberti KG, Eckel RH, Grundy SM, et al. Harmonizing the metabolic syndrome: a joint interim statement of the international diabetes federation task force on epidemiology and prevention; national heart, lung, and blood institute; American heart association; world heart federation; international atherosclerosis society; and international association for the study of obesity. Circulation. 2009;120 (16):1640-1645. doi:10.1161/CIRCULATIONAHA.109.192644

29. Tong J, Boyko EJ, Utzschneider KM, et al. Intra-abdominal fat accumulation predicts the development of the metabolic syndrome in non-diabetic Japanese-Americans. Diabetologia. 2007;50 (6):1156-1160. doi:10.1007/s00125-007-0651-y

30. Shah RV, Murthy VL, Abbasi SA, et al. Visceral adiposity and the risk of metabolic syndrome across body mass index: the MESA study. JACC Cardiovasc Imaging. 2014;7(12):1221-1235. doi:10.1016/j.jcmg.2014.07.017

31. Park HS, Lee K. Greater beneficial effects of visceral fat reduction compared with subcutaneous fat reduction on parameters of the metabolic syndrome: a study of weight reduction programmes in subjects with visceral and subcutaneous obesity. Diabet Med. 2005;22(3):266-272. doi:10.1111/dme.2005.22.issue-3

32. Wajchenberg BL. Subcutaneous and visceral adipose tissue: their relation to the metabolic syndrome. Endocr Rev. 2000;21 (6):697-738. doi:10.1210/edrv.21.6.0415

33. Sam S. Differential effect of subcutaneous abdominal and visceral adipose tissue on cardiometabolic risk. Horm Mol Biol Clin Investig. 2018;33(1).

34. Mårin P, Andersson B, Ottosson M, et al. The morphology and metabolism of intraabdominal adipose tissue in men. Metabolism. 1992;41(11):1242-1248. doi:10.1016/0026-0495(92)90016-4

35. Ibrahim MM. Subcutaneous and visceral adipose tissue: structural and functional differences. Obes Rev. 2010;11(1):11-18. doi:10.1111/ obr.2010.11.issue-1

36. Fried SK, Bunkin DA, Greenberg AS. Omental and subcutaneous adipose tissues of obese subjects release interleukin-6: depot difference and regulation by glucocorticoid. J Clin Endocrinol Metab. 1998;83(3):847-850. doi:10.1210/jcem.83.3.4660

37. Bruun JM, Lihn AS, Pedersen SB, Richelsen B. Monocyte chemoattractant protein-1 release is higher in visceral than subcutaneous human adipose tissue (AT): implication of macrophages resident in the AT. J Clin Endocrinol Metab. 2005;90(4):2282-2289. doi:10.1210/jc.2004-1696

38. Fontana L, Eagon JC, Trujillo ME, Scherer PE, Klein S. Visceral fat adipokine secretion is associated with systemic inflammation in obese humans. Diabetes. 2007;56(4):1010-1013. doi:10.2337/db06-1656
39. Pontiroli AE, Frige F, Paganelli M, Folli F. In morbid obesity, metabolic abnormalities and adhesion molecules correlate with visceral fat, not with subcutaneous fat: effect of weight loss through surgery. Obes Surg. 2009;19(6):745-750. doi:10.1007/s11695-008-9626-4

40. Ritchie SA, Connell JM. The link between abdominal obesity, metabolic syndrome and cardiovascular disease. Nutr Metab Cardiovasc Dis. 2007;17(4):319-326. doi:10.1016/j.numecd.2006.07.005

41. Chae JS, Paik JK, Kang R, et al. Mild weight loss reduces inflammatory cytokines, leukocyte count, and oxidative stress in overweight and moderately obese participants treated for 3 years with dietary modification. Nutr Res. 2013;33(3):195-203. doi:10.1016/j. nutres.2013.01.005

42. Knowler WC, Barrett-Connor E, Fowler SE, et al. Reduction in the incidence of type 2 diabetes with lifestyle intervention or metformin. $N$ Engl J Med. 2002;346(6):393-403.

43. DeBoer MD, Filipp SL, Gurka MJ. Use of a metabolic syndrome severity $\mathrm{Z}$ score to track risk during treatment of prediabetes: an analysis of the diabetes prevention program. Diabetes Care. 2018;41(11):2421-2430. doi:10.2337/dc18-1079

44. de Mutsert R, Gast K, Widya R, et al. Associations of abdominal subcutaneous and visceral fat with insulin resistance and secretion differ between men and women: the Netherlands Epidemiology of Obesity Study. Metab Syndr Relat Disord. 2018;16(1):54-63. doi:10.1089/met.2017.0128

45. Ng TW, Watts GF, Barrett PH, Rye KA, Chan DC. Effect of weight loss on LDL and HDL kinetics in the metabolic syndrome: associations with changes in plasma retinol-binding protein-4 and adiponectin levels. Diabetes Care. 2007;30(11):2945-2950. doi:10.2337/dc070768

46. Ng TW, Chan DC, Barrett PH, Watts GF. Effect of weight loss on HDL-apoA-II kinetics in the metabolic syndrome. Clin Sci (Lond). 2009;118(1):79-85. doi:10.1042/CS20090110

47. Park HS, Sim SJ, Park JY. Effect of weight reduction on metabolic syndrome in Korean obese patients. J Korean Med Sci. 2004;19 (2):202-208. doi:10.3346/jkms.2004.19.2.202

48. Devers MC, Campbell S, Simmons D. Influence of age on the prevalence and components of the metabolic syndrome and the association with cardiovascular disease. BMJ Open Diabetes Res Care. 2016;4(1):e000195. doi:10.1136/bmjdrc-2016-000195

49. Wang WS, Wahlqvist ML, Hsu CC, Chang HY, Chang WC, Chen CC. Age- and gender-specific population attributable risks of metabolic disorders on all-cause and cardiovascular mortality in Taiwan. BMC Public Health. 2012;12:111. doi:10.1186/1471-245812-111

Diabetes, Metabolic Syndrome and Obesity: Targets and Therapy

\section{Publish your work in this journal}

Diabetes, Metabolic Syndrome and Obesity: Targets and Therapy is an international, peer-reviewed open-access journal committed to the rapid publication of the latest laboratory and clinical findings in the fields of diabetes, metabolic syndrome and obesity research. Original research, review, case reports, hypothesis formation, expert opinion and commentaries are all considered for publication. The manuscript management system is completely online and includes a very quick and fair peer-review system, which is all easy to use. Visit http://www.dovepress.com/testimonials.php to read real quotes from published authors.

Submit your manuscript here: https://www.dovepress.com/diabetes-metabolic-syndrome-and-obesity-targets-and-therapy-journal 